\title{
INTEROPERABILITY IN PEDAGOGICAL ELEARNING SERVICES
}

\author{
Ricardo Queirós \\ CRACS/FCUP \& DI-ESEIG/IPP, Porto, Portugal \\ ricardo.queiros@eu.ipp.pt
}

Keywords: eLearning; Interoperability; Service Oriented Architectures.

\begin{abstract}
The ultimate goal of this research plan is to improve the learning experience of students through the combination of pedagogical eLearning services. Service oriented architectures are already being used in eLearning but in this work the focus is on services of pedagogical value, rather then on generic services adapted from other business systems. This approach to the architecture of eLearning platforms raises challenges addressed by this work, namely: conceptual modeling of the pedagogical eLearning services domain; interoperability and coordination of pedagogical eLearning service; conversion of existing eLearning systems to pedagogical services; adaptation of eLearning services to individual learners. An improved eLearning platform will incorporate learning tools adequate to the domains it covers and will focus on the individual learner that uses it. With this approach we expect to raise the pedagogical value of eLearning platforms
\end{abstract}

\section{MOTIVATION}

The majority of the eLearning platforms available today follow a component-oriented architecture. These systems assemble a collection of generic tools - such as forums or multiple choice quizzes - that are considered to be useful for all subjects. Despite their success, they have also been target of criticism that led to recent initiatives to adapt Service Oriented Architecture (SOA) to eLearning. The pressure to adopt SOA in eLearning is mostly fuelled by managerial needs of academic institutions, rather than pedagogical concerns of teachers. In some cases is an internal need, of combining infrastructures of autonomous departments with different responsibilities within an academic institution. In other cases results from external pressure, of linking with other institutions in order to offer join eLearning programs.

An alternative view of eLearning services is to use them to extend the pedagogical features of eLearning platforms. Traditionally, these features are added to eLearning systems by integration of new components. These components are system specific and tend to be very general, in order to be reusable in as many situations as possible. As for components, services are easy to add and replace in a system but, unlike components, services are easy to restructure to implement new processes, usually business processes. This approach can also be extended to learning processes in order to create an instructional environment more adapted to the student needs and requirements. For instance, existing eLearning platforms do not provide specific tools for solving programming exercises in computer science courses, playing business games in management courses, or simulating a human patient in life sciences courses. These tools would be too specific to incorporate in a eLearning platform. Even if they could be provided as pluggable components, the burden of maintaining them would be prohibitive to institutions with few courses in those domains. On the other hand, a programming exercise evaluation engine, a business game engine or a patent simulator can provide their services to many eLearning systems. In turn, these services can be clients of other services, such as repositories of specialized Learning Objects (LO), or generators of LO. The selection of LO can be mediated by another service that adapts its results to the needs and preferences of students.

The ultimate goal of this work is to improve the students' learning experience through the combination of pedagogical eLearning services. To 
achieve this goal it is necessary to fulfill both abstract and concrete requirements. Firstly, it requires a categorization of types of pedagogical eLearning services to support the definition of an interaction model for this class of services. Secondly, it requires also a reasonable number of actual pedagogical eLearning services, both general - such as repositories of learning objects - and specialized - such as evaluator of programming problems.After returned the manuscript must be appropriately modified.

\section{STATE OF THE ART}

The evolution of eLearning systems comprises the last two decades. In their first generation eLearning systems were developed for a specific learning domain and had a monolithic architecture (Dagger, 2007). Gradually, these systems evolved and became domain-independent, featuring reusable tools that can be effectively used virtually in any eLearning course. The systems that reach this level of maturity usually follow component oriented architecture in order to facilitate tool integration. An example is Learning Management Systems (LMS) that integrate several types of tools for delivering content and for recreating a learning context.

The present generation values the interchange of learning objects and learners' information through the adoption of new standards that brought content sharing and interoperability to eLearning. Standards can be viewed as "documented agreements containing technical specifications or other precise criteria to be used consistently as guidelines to ensure that materials and services are fit for their purpose" (Bryden, 2006). In the eLearning context, standards are generally developed for the purposes of ensuring interoperability and reusability in systems and in the content and meta-data they manage. In this context, several organisations (IMS, IEEE, ISO/IEC) have develop specifications and standards in the last years (Friesen, 2005). These specifications define, among many others, standards for eLearning content (IMS-CP, IMS_MD, IMSQTI) and interoperability (IMS-DRI) (Simon, 2005). These integrated environments have been successfully used to leverage the advantages of ICTs, but have also been target of criticism (Dagger, 2007). Examples of these criticisms are the excessive focus on content, the lack of support to specific needs and the difficulty to integrate with other eLearning systems. These shortcomings triggered the appearance of initiatives (Smythe,
2003), (OKI, 2005), (Wilson, 2004) to adapt Service Oriented Architecture (SOA) to eLearning. These new frameworks and APIs contributed with the identification of service usage models and are grouped into logical clusters according to their functionality (Aguirre, 2006).

The service oriented architecture is appropriate in contexts where exists a combination of several different components that needs flexibility in their configuration. The communication between these components is based generally on web services (WS). The Web Service Description Language (WSDL) provides a description of how to use a WS but not how several WSs cooperate to achieve a given goal. This issue is handled by several specifications that use orchestration (WS-BPEL, 2007), (Weerawarana , 2007) and/or choreography (WS-CDL, 2004) to define an interoperable integration model. This model facilitates the expansion of automated process integration and the management of the workflow within services (Feier, 2005).

Personalised adaptive learning is also a new area of research at the crossroads of the Intelligent Tutoring Systems (Wenger, 1987), Adaptive Hypermedia (Brusilovsky , 2001) and Multi-agent systems (Lin, 2005). In adaptation and personalisation the user plays a fundamental role in the system's design. Representing user profile data is just one step (IMSLIP, 2001), (PAPI, 2000) of the process. Their semantic differences raise several interoperability issues when they need to be distributed (Aroyo , 2006). It should be noted that adaptive learning has not yet been adequately addressed in any eLearning specification or standard (Manjón , 2007) and is one of the main topics of research groups, such as, $\mathrm{aDeNu}$ and e-UCM.

Apart from the user model, another important topic is the instruction model that specifies the navigational design ("flows") for an adaptive hypermedia application. Several specifications (IMS-SS, 2003), (IMS-LD, 2003) were create to deal with the design of pedagogical activities, but designing more complex adaptive behaviour are still hard to achieve (Aroyo, 2006).

\section{OUTLINE OF OBJECTIVES}

The main goal of this work is to improve the students learning experience through the combination of pedagogical eLearning services. The tasks described in the following sub-sections 
contribute to this goal, each one with specific objectives.

\subsection{Conceptual Model}

The main objective in this task is to formalise a conceptual model of the domain of pedagogical services. We will start by identifying and characterising the main concepts in this domain services and actors - and the relationship among them. We will study the service genres identified by existing eLearning frameworks (Smythe, 2003), (OKI, 2005), (Wilson, 2004) and extend then to pedagogical services. Examples of pedagogical services are authoring tools, evaluation engines, specialised repositories, etc. For instance, the class of authoring tools includes Integrated Development Environments (IDE) commonly used for developing computer programs. A system of this type can be extended to provide an authoring service to a pedagogical process for learning a computer programming language. The IDE will consume other pedagogical services: it will load programming problems from a specialised repository, will submit the learner's solution to an evaluation engine and report results to a Learning Management System (LMS) with a grade book. In this model we intend to characterise classes of pedagogical eLearning systems by the type of services they provide and consume.

We will focus on pedagogical services but we will also cover other support services required by any SOA platform (e.g. security). The model will precise also the role of actors - students, teachers, and staff with relation to services they use. We expect to define this conceptual model using Web services ontologies (OWL, 2007).

\subsection{Interaction}

In this task the main objective is to specify interoperation of pedagogical eLearning services. We will start by studying the classic models of integration, with emphasis on service based integration. Based on our early work implementing a repository of Learning Objects (LO) as a service, we will consider different web services flavours, namely SOAP and REST. The former are based on W3C specifications but are more complex and require specialised SOAP engines. The latter have an informal specification, are straightforward to implement and more efficient. Service definition in the WS-SOAP framework is based on the WSDL language. The current version of this language has already support for semantic annotations using RDF - a standard XML language used for representing OWL ontologies. This fact is a strong point in favour of SOAP. Nevertheless, we will seek alternative service representations with support for semantic descriptions, compatible with REST.

Using semantic Web methodologies and associated technologies we will explore different ways to improve eLearning services. Services may use a commonly agreed semantic based language for sharing concepts. Users can describe their situation (goal of learning, previous knowledge, etc) and services may perform semantic querying for the suitable learning material. Information may be active delivered (based on personalised services) to create a dynamic learning environment integrated in the host institution business processes. Learning Objects (LO) are distributed on the web, but they may be linked to commonly agreed ontologie(s) to help the discovery of what the LO is about.

Service discovery and coordination (e.g. orchestration, choreography) are main issues that we have also to address. The main goal is to enable semantic mapping and the coordination of eLearning services. For coordinating eLearning processes we will explore two alternatives: orchestration and choreography. The former is a standard central coordination approach; it can be implemented using Business Process Modelling (BPM) engines that perform orchestration running process descriptions written in languages such as BPEL. The latter is a self coordination approach that has not reach the same level of maturity.

The expected result of this task is a model for interaction among pedagogical eLearning services. This model will build on the characterisation of services defined by the previous task.

\subsection{Integration}

As proof of concept, we will need a critical mass of services to implement the previously achieved models in a specific learning domain - the automatic evaluation of programming problems. Moreover, to test the previous approaches, such as semantic web and web adaptivity, we need actual eLearning services with true pedagogical content. In this task we will recast existing eLearning systems as services. In the defined domain - the automatic evaluation of programming problems - we want to support all the life cycle of a programming problem, since its creation, searching, solving and evaluation. We will use different services types, covering the categorisation resulting from the first task, based on 
existing eLearning systems. Candidates to provide these services are:

- a repository of learning objects - e.g. crimsonHex (Leal and Queirós, 2008) - to provide persistent storage, search and download of LO and related metainformation;

- an evaluation engine - e.g. Mooshak (Leal and Silva, 2008) - to evaluate and produce feedback to the learners problem's attempts.

- An LMS (e.g. Moodle) - to manage and retrieve the exercises to the learners.

Our novel idea is to integrate an IDE in the actual infrastructure. This integration will provide the student an interactive and assisted environment in the resolution of problems. This idea resulted from the need to address the lack of integration of intelligent codification environments in the process of solving programming exercises. The integration includes the following steps: study of IDEs "open source" (Eclipse, NetBeans, etc.) and the several integration levels of components in the IDEs platforms, namely: by invocation, by sharing data, through API's (Application Programming Interface), based in UIs (User Interface) and through PDEs (Plug-In Development Environment).

In this task we expected to recast existing eLearning systems as services, as well as create brand new services identified in the first task. The recasting of existing systems as services will be the least intrusive possible in order to share and support the previously created models.

\subsection{Adaptability}

This task's objective is to use approaches from hypermedia adaptability to enhance pedagogical eLearning services. Adaptability is typically used within content or to select among alternative contents. In this setting, adaptability can also be used to dynamically combine eLearning services. To address the lack of focus on the learner, a major problem in existing component-based eLearning systems, we will adapt services to the requirements of students and, ultimately, to provide adaptability as a service itself, that adds value to eLearning processes. This challenge includes and expands the goals of web adaptivity, since we are interested in adapting not only the web user interface, but also functions exposed by web services. Pedagogical services will provide functions for collecting information on students and their activity. This stream of information will be used for understanding their behaviour and predicting their needs., using: 1) a data-warehousing service for collecting and storing relevant information; 2) monitoring tools for computing indicators (metrics) and infer measures of success of the learning process; and 3) adaptation services that use the activity information that predicting models for other pedagogical eLearning services.

As said before, we will try to provide adaptability itself as a pedagogical eLearning service, independent from domain specific services. The expected result of this task is a set of mechanisms for coordination of the learning process based on the profiles of the students, adjusted to their needs and preferences.

Other research path is the articulation and dynamic sequencing of instructions based on existing standards for sequencing and navigation (IMS-SS, 2003), (IMS-LD, 2003). These specifications aims to provide to the teachers mechanisms for coordination of the educational instructions based on students' profile making the instruction more dynamic and flexible. In this research path we will study the existing standards for sequencing and navigation and implement dynamic sequencing in a LMS.

\subsection{Evaluation}

In a final task the objective is to validate the proposed approach by testing the conformance to the initial requirements - interoperability and adaptability. A set of pedagogical process for programming language instruction will be created to support this evaluation. Other specific domains will be considered, such as, managing remote electronics laboratory activities that uses specific hardware resources (micro-controllers, oscilloscopes, among others). The evaluation will be characterised by a definition of set-up live experiments with real students, enrol within courses of the domains described early. This phase will allow us to validate our work in production scenarios and measure the adhesion of the students to the eLearning platform.

\section{EXPECTED OUTCOME}

The aim of this $\mathrm{PhD}$ work-plan is the improvement of eLearning platforms based on service oriented architectures by focusing on the learner and on the learning subjects. It addresses the fundamental problems of creating such service oriented eLearning infrastructure - interoperability and adaptability - and the production of a collection of 
services on which to base eLearning platforms, which will be used as test bed for validation and future research. We envision a federation of pedagogical eLearning systems, including those already in use nowadays, providing their services to several eLearning platforms. These pedagogical services will add value to the learning process, contributing either with content/context to a specific learning domain, or with its adaptation to the needs and preferences of a particular student. These services interoperate seamlessly, ensure security and will be reusable in different learning processes.

\section{CALENDAR}

I am currently on the initial stage of my $\mathrm{PhD}$ work. The planned calendar for the tasks presented in section 3 is the following:

- Task 1 - Conceptual Model [Jan 2009 to Aug 2009];

- $\quad$ Task 2 - Interaction [Sep 2009 to Feb 2010];

- Task 3 - Integration [Mar 2010 to Sep 2010];

- Task 4 - Adaptability [Oct 2010 to May 2011];

- $\quad$ Task 5 - Evaluation [Jun 2011 to Aug 2011];

- Task 6 - Dissertation [Sep 2011 to Dec 2011].

\section{REFERENCES}

Dagger, D., O'Connor, A., Lawless, S., Walsh, E., Wade,V. Service Oriented eLearning Platforms: From Monolithic Systems to Flexible Services, https://www.cs.tcd.ie/ slawless/ papers/ieee2007.pdf

Bryden, A. Open and Global Standards for Achieving an Inclusive Information Society.

IMS Global Learning Consortium. URL: http://www.imsglobal.org

IEEE Learning Technology Standards Committee. URL: http://ieeeltsc.org

ISO/IEC - International Organisation for Standardisation. URL: http://standards.iso.org/ittf/

PubliclyAvailableStandards /index.html

Friesen, N. Interoperability and Learning Objects: An Overview of E-Learning Standardization". Interdisciplinary Journal of Knowledge and Learning Objects. 2005.

IMS-CP - IMS Content Packaging. URL: http://www.imsglobal.org/ content/packaging/.

IMS-Metadata - IMS Meta-Data. URL: http://www.imsglobal.org/metadata/.

IMS-QTI - IMS Question and Test Interoperability. URL: http://www.imsglobal.org/question/index.html.

IMS DRI - IMS Digital Repositories Interoperability URL: http://www.imsglobal.org/digitalrepositories/driv1p0/i msdri_infov1p0.html

Simon, B., Massart, D., van Assche, F., Ternier, S., Duval, E., Brantner, S., Olmedilla, D., \& Miklos, Z. A Simple Query Interface for Interoperable Learning Repositories. In Proceedings of the WWW 2005 Conference.

Smythe, C. IMS Abstract Framework - A review, IMS Global Learning Consortium, Inc. 2003.

Open Knowledge Initiative Website, http://www.okiproject.org.

Wilson, S., Blinco, K., Rehak,D. An e-Learning Framework - Paper prepared on behalf of DEST (Australia), JISC-CETIS (UK), and Industry Canada, July 2004.

Aguirre, S., Salvachúa, J., Fumero, A., Tapiador, A. Joint Degrees in E-Learning Systems: A Web Services

Approach". Collaborative Computing: Networking, Applications and Worksharing, 2006.

WS-BPEL - Web Services Business Process Execution Language Version 2.0 - OASIS Standard -11 April 2007

Weerawarana, S., Curbera, F. Business Process with BPELAWS: Understanding BPELAWS, Part 1,

http://www-128.ibm.com/developerworks/webservices/ library/ws-bpelcol1/, 2006.

WS-CDL - "WS Choreography Model Overview" - W3C Working Draft - 24 March 2004.

Feier, C., Polleres, A., Dumitru, R., Domingue, J., Stollberg, M., Fensel, D. Towards intelligent web services:The web service modeling ontology (WSMO)". International Conference on Intelligent Computing (ICIC), 2005.

Wenger, E. Artificial Intelligence and Tutoring Systems, CA, USA: Morgan Kaufman, 1987.

Brusilovsky, P. Adaptive Hypermedia. User Modelling and User-Adapted Interaction, 11, 87-110. 2001.

Lin, F. O. Designing Distributed Learning Environments with Intelligent Software Agents, London: Information Science Publishing. 2005.

IMS-LIP (2001). IMS Learner Information Package, URL: http://www.imsglobal.org/profiles/.

IEEE Public And Private Information (PAPI). URL: http://jtc1sc36.org/doc/36N0186.pdf .

Aroyo, L., Dolog, P., Houben, G., Kravcik, M., Naeve, A., Wild, F. Interoperability in Personalized Adaptive Learning". Educational Tecnhnology \& Society, 2006.

Manjón,B. Standards-based Adaptive e-Learning Services", AdaptLearn research project, 2007.

IMS-SS (2003). IMS Simple Sequencing Information and Behavior Model - Version 1.0 Final Specification. URL: http://www.imsglobal.org/simplesequencing/ ssv1p0/imsss_infov1p0.htm

IMS-LD (2003). IMS Learning Design. URL: http://www.imsglobal.org/learningdesign/.

OWL - Web Ontology Language. URL: http://www.w3.org/TR/owl-guide.

Leal, J. P., Queirós, R. Design of a Repository of Programming Problems. The 2008 Competitive 
Learning Symposium, ACM-ICPC World Finals, Banff, Canada, April, 2008.

Leal, J.P., Silva, F. Using Mooshak as a Competitive Learning Tool. The 2008 Competitive Learning Symposium, ACM-ICPC World Finals, Banff, Canada, April, 2008. 